\title{
Rapid Determination of Bacteria in Drinking Water Using an ATP Assay
}

\author{
Rolf A. Deininger and JiYoung Lee \\ Department of Environmental Health Sciences, School of Public Health, The University of Michigan, \\ Ann Arbor, Michigan 48109
}

Received 20 April 2001; revised 12 May 2001; accepted 22 May 2001

\begin{abstract}
The presently used heterotrophic plate count (HPC) for the evaluation of the total number of bacteria in a sample of drinking water takes 7 days of incubation. When the results are known, the water has been consumed and is ineffective for the protection of the health of the consumers. Operators of water treatment systems need to know the bacterial water quality in near real time. Contamination of the system, whether it is intentional, accidental, or due to an inadequate disinfectant residual needs to be discovered much sooner because intervention can then take place in the form of flushing low quality water and/or raising the disinfectant residual. The purpose of this study was therefore to determine if a rapid ATP assay can estimate the HPC in minutes. Two additional methods were used for some samples. The first method was the acridine orange direct count (AODC) that enumerates both viable and nonviable bacteria. The second method was the direct viable count (DVC) that enumerates only viable bacteria. Water samples were obtained from local, national, and international locations. The sample selection criteria were based on proximity to the laboratory, cooperating water utilities, and the travel of the authors. The results of the study show that the rapid ATP assay is highly correlated with the conventional plate count method and the DVC method. The significance of the ATP assay is that it can determine the bacterial quality of the drinking water in less than 5 min. (c) 2001 John Wiley \& Sons, Inc. Field Analyt Chem Technol 5: 185-189, 2001
\end{abstract}

Keywords: drinking water; bacterial quality; rapid method; on-site analysis; ATP bioluminescence

\section{Introduction}

Federal regulations regarding the microbiological quality of drinking water focus on a single group of indicator organisms, the coliforms, for the bacteriological safety of the water. ${ }^{1}$ Although these standards of water quality

Correspondence to: Rolf A. Deininger; e-mail: rad@umich.edu.

(c) 2001 John Wiley \& Sons, Inc. have reduced massive outbreaks of waterborne diseases, they have been questioned whether or not they are adequate to prevent waterborne illnesses. ${ }^{2}$ Cases of gastrointestinal illnesses have been reported among individuals drinking tap water that had met microbiological, physical, and chemical water-quality criteria. The determination of the total number of heterotrophic bacteria (HPC) has been known to be a better indicator of water quality than the coliform test because many opportunistic pathogens are not in the coliform group. ${ }^{3}$ Furthermore, a high HPC interferes with the determination of the coliforms. ${ }^{4}$

The present HPC method using R2A agar is the most sensitive test for enumerating the total number of bacteria in treated water. ${ }^{5}$ The disadvantage of the test is that it takes 7 days to complete and when the results are known, the water has long been consumed. A test is needed that determines the total bacterial populations in a very short time so that corrective actions can be taken in a timely manner.

The ATP bioluminescence assay allows an estimation of bacterial populations within minutes and it can be done on-site. The estimation of the bacterial count based on a ATP assay of the water is not new. Standard Methods (1995; 9211C.1) indicate that the test requires $1 \mathrm{~h}$ and 11 of water. ${ }^{6}$ The test has a sensitivity of 100,000 cells. What is new is that the method presented here is over 100 times more sensitive, requires one-hundredth of the sample volume, and is over 10 times faster.

Thus, the purpose of this study was to determine if a rapid ATP assay could estimate the bacterial populations in a practical and timely manner. To check the accuracy of both the ATP and the HPC test, a direct enumeration of the bacteria in a water sample was done using two epifluorescence methods. One was the Acridine Orange Direct Count (AODC) method to enumerate the total number of bacteria, which include both the viable cells and the nonviable cells. The other was the Direct Viable Count (DVC) method, which selectively enumerates only viable bacteria. These two tests 
are very time consuming and require high technical skills and are not normally done by operators of water-treatment systems.

\section{Materials and Methods}

\section{Water Samples}

Several water utilities in various states (Michigan, Ohio, California, Colorado, Georgia, and Florida) cooperated in the study and provided samples of their drinking water. Additional water samples were taken from airport locations (Illinois, California, Oregon, Washington, Kentucky, Tennessee, Maryland, Texas, and New York). Other samples were taken from drinking water fountains in Michigan, Ohio, Illinois, Washington, DC, California, Colorado, Florida, Georgia, Oregon, Washington, Kentucky, Tennessee, Maryland, Texas, and New York. No attempt was made to have a sampling plan to cover the entire United States and thus all samples may be considered convenience samples. To see if the test would also work with drinking water samples from abroad, a number of worldwide samples were obtained over a period of 2 years from Hungary, Germany, Switzerland, The Netherlands, Austria, United Kingdom, France, Ukraine, Lithuania, Japan, Korea, Egypt, Saudi Arabia, Argentina, Peru, Brazil, Panama, and Australia. Again this set of samples does not cover the entire world, and must also be considered as a convenience-sample set.

\section{Filtration of the Water Samples}

Based on the expected bacterial count of the water sample an amount between 0.1 and $10 \mathrm{ml}$ was drawn into a sterile syringe. The usual volume of water filtered was typically $10 \mathrm{ml}$. After drawing the water into the syringe, a filter holder with a Filtravette $^{\mathrm{TM}}$ was attached to the syringe and the water sample was pressed through the filter. The Filtravette is a combination of a filter with pore size of $0.45 \mu \mathrm{m}$ and a cuvette. The filter holder used in the study was a Swinex filter holder (13 mm; Millipore Corporation, Bedford, MA). After filtration the Filtravette was removed from the filter holder and placed onto a sterile blotting paper. The water remaining inside the Filtravette was removed with a converted 3-ml syringe by applying gentle air pressure.

\section{ATP Bioluminescence}

A two-step procedure is necessary to separate the somatic-cell ATP from the bacterial-cell ATP. A somaticcell-releasing agent (New Horizons Diagnostic Corporation [NHD], Columbia, MD) was used to lyse all non-bacterial cells and release their ATP. Air pressure was used to remove the nonbacterial ATP through the filter. At this stage, the Filtravette retained the bacteria on its surface, and the bacterial ATP remained within the bacterial cell membranes through this step of the procedure. The Filtravette was then inserted into the microluminometer (Model 3550, NHD, Columbia, MD) and the bacterial-cell-releasing agent was added to lyse the bacterial cells retained on the surface of the filter. The released bacterial ATP was mixed with 50 $\mu l$ of luciferin-luciferase (NHD, Columbia, MD) and the drawer of the microluminometer was closed. The light emission was recorded over a 10-s time interval and the light impulses were integrated. The unit of measurement of the luminometer is relative light units (RLU). The result was expressed as RLU/ml by dividing the RLU values by the filtered water volume. The detection limit and sensitivity of the luminometer was tested with serially diluted ATP solutions (NHD, Columbia, MD). Distilled deionized water was used for the dilution at a $\mathrm{pH}$ of 7.8. The activity of the luciferin-luciferase was checked by using an ATP standard (NHD, Columbia, MD). The RLUs are proportional to the amount of ATP, and the amount of ATP is proportional to the number of viable bacteria. The luminometer and the required accessories fit nicely onto a clipboard and are shown in Fig. 1.

\section{Bacterial Enumeration: $A O D C, D V C, H P C$}

Three different methods were used to enumerate the bacteria. The first two methods count the number of individual cells. The latter method counts the number of colonies growing on an agar dish after an incubation time of 7 days.

AODC. The AODC is a method that determines the total number of viable and nonviable bacteria. The bacteria are fixed with formaldehyde ( $2 \%, \mathrm{v} / \mathrm{v}$, final concentration). ${ }^{7}$ The bacterial cells are then stained with acridine orange $(0.01 \%, w / v$, Fluka, Switzerland) after filtration onto a $0.2 \mu \mathrm{m}$ pore-size black polycarbonate membrane filters (Poretics, Livermore, CA). The cells were then counted under a magnification of $\times 1000$ with an Olympus Provis epifluorescence microscope (Olympus Optical Co., Japan) equipped with a mercury arc lamp and a 460-490 nm excitation filter. The number of bacteria was counted in 10 microscopic fields by using three sub samples and was averaged. The number of bacteria per milliliter of sample was calculated using the formula in Standard Methods. ${ }^{6}$ The method requires high technical skills and also requires judgment in identifying which of the stained images represents a cell. The method cannot distinguish living cells from dead cells.

DVC. The DVC is a method that identifies only living cells. ${ }^{8}$ The samples were incubated with yeast extract $(0.005 \%, w / v$, Difco, Detroit, MI) and nalidixic acid (10 mg/L, Sigma, St. Louis, MO) without dilution for $24 \mathrm{~h}$ at $20^{\circ} \mathrm{C}$. The modifications from the original method consisted of using a lower concentration of yeast extract and no dilution. After incubation, fixation, counting, and calculation of elongated bacteria, followed the AODC method. Under the microscope, only living cells will show their typical elongated form. Thus this method is the most accurate, but also most time-consuming method.

HPC. The HPC was determined for each water sample in triplicate using R2A medium (Difco, Detroit, Michigan). The bacterial colonies on the agar plates 


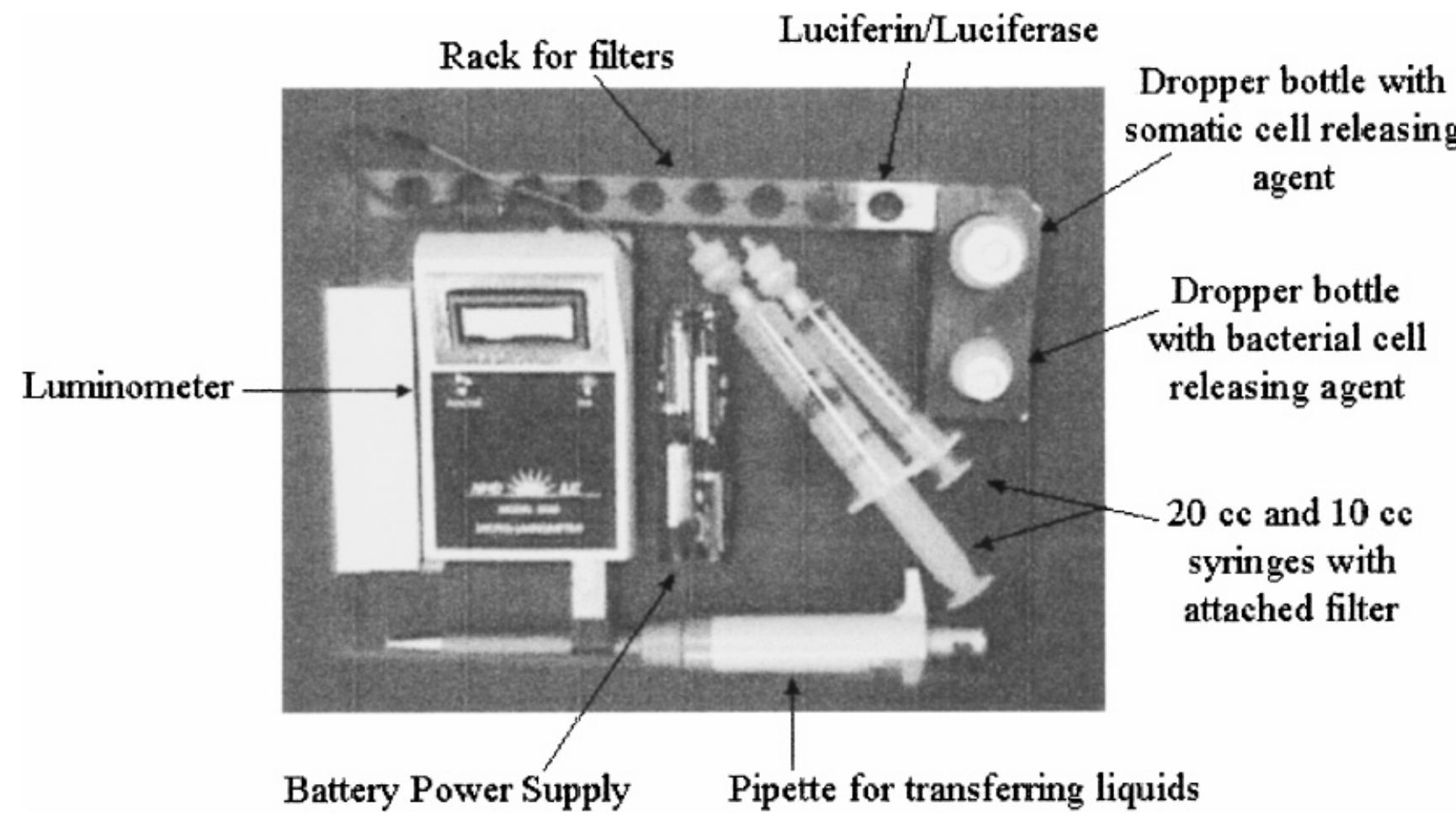

FIG. 1. Portable microluminometer with all accessories on a clipboard.

were counted after an incubation period of 7 days at $28^{\circ} \mathrm{C}$.

\section{Results and Discussion}

\section{Correlation Between Parameters}

The detection limit of ATP assay was determined with multiple serial dilutions. It showed that the microluminometer was able to determine ATP concentrations as low as 0.2 pg. ${ }^{9}$ It is known that the average ATP content of one bacterial cell is about $10^{-15} \mathrm{~g}(1 \mathrm{fg}) .{ }^{10}$ Thus the detection limit of $0.2 \mathrm{pg}$ corresponds to about 200 bacterial cells.

About 120 water samples from the United States alone were analyzed with ATP bioluminescence, HPC, DVC, and AODC methods (each in triplicate). A statistical analysis of the data showed that there is a high correlation between ATP, HPC, DVC, and AODC. The correlation coefficient between ATP and HPC was 0.84, and the correlation coefficient between ATP and DVC was 0.8 . Both were statistically highly significant $(p<0.05)$. In Fig. 2 the relation between HPC and ATP is shown for samples from the United States, and in Fig. 3 the same relation from worldwide samples is shown. The relation between DVC and ATP is shown in Fig. 4. The fact that the regression line does not go through the origin may be due to the detection limit of the ATP. That is, over 200 cells are necessary to get a response from the luminometer. And finally, in Fig. 5 the relationship between AODC and ATP is shown. Again the intercept at the $y$-axis may be due to the fact that the AODC method counts both living and dead cells, while the ATP assay determines only living cells.

Intentional Contamination of a Water Supply System

Contamination of water supply systems has its root in antiquity. In biological warfare the preferred route is airborne through aerosols, but the water route cannot be excluded. Targets in the latter route are the sources of the water supply system, lakes and rivers, the treatment plant, and the water

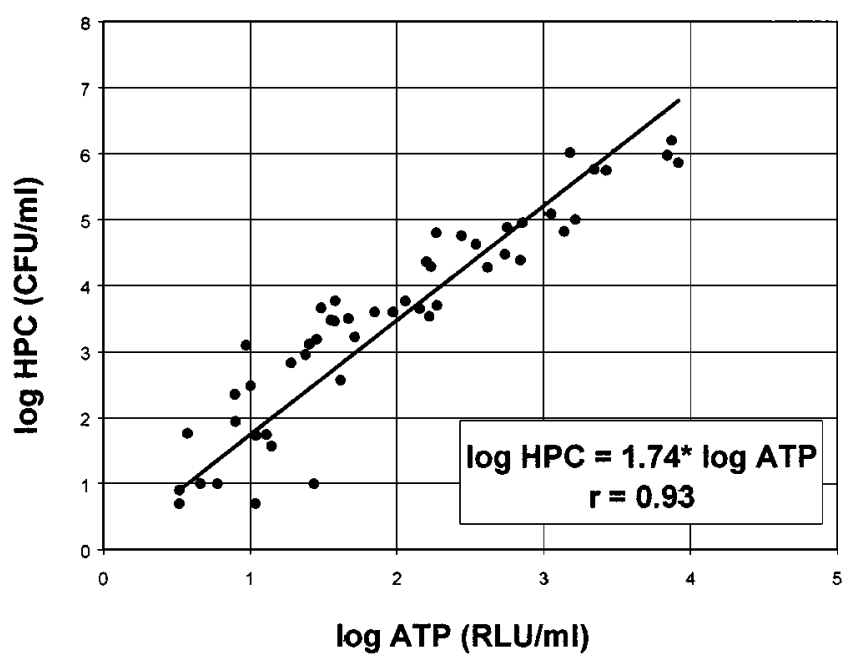

FIG. 2. HPC vs. ATP for U.S. water supplies. 


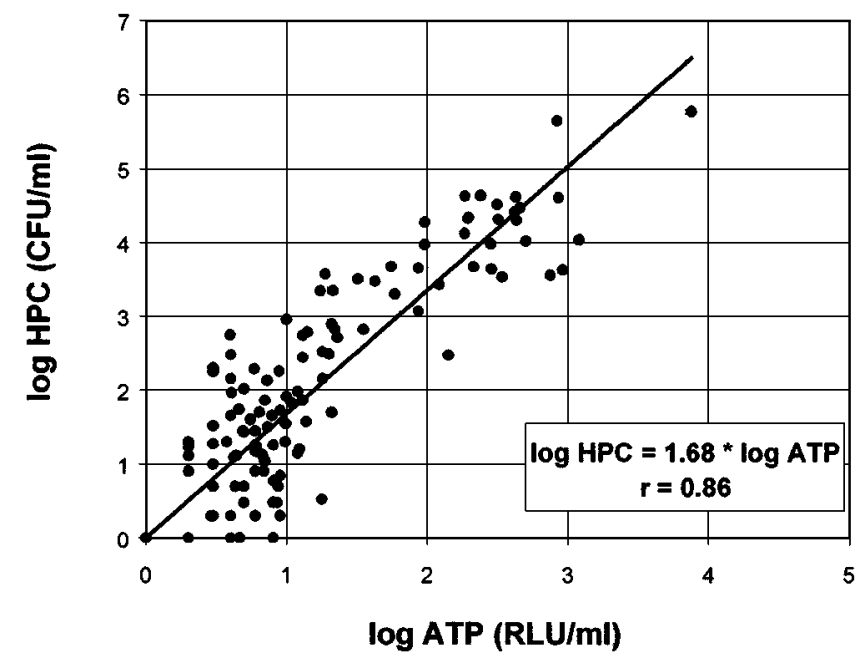

FIG. 3. HPC vs. ATP for international water samples.

distribution system. The most likely point of attack would be after the treatment plant. Prime targets are the reservoirs and the water distribution pipes. Consider a biological agent such as bacteria that has an infectious dose of a million cells. To be effective, that dose would have to be contained in a glass of water $(200 \mathrm{ml})$. If one takes a $10-\mathrm{ml}$ sample of the contaminated water, one would collect about 50,000 organisms. Since the detection limit is well below 1000 organisms, detection poses no problem. If the infectious dose is 1000 organisms, then a $60-\mathrm{ml}$ sample (a $60-\mathrm{cc}$ syringe) of the glass of water would contain about 300 organisms and one would be at the detection limit of the method. Operating at this level would require a concentration step using larger sample volumes and an additional filtration step. Thus, an intentional contamination of a water supply system can be detected. The question is if it can be done in time. A near continuous monitoring

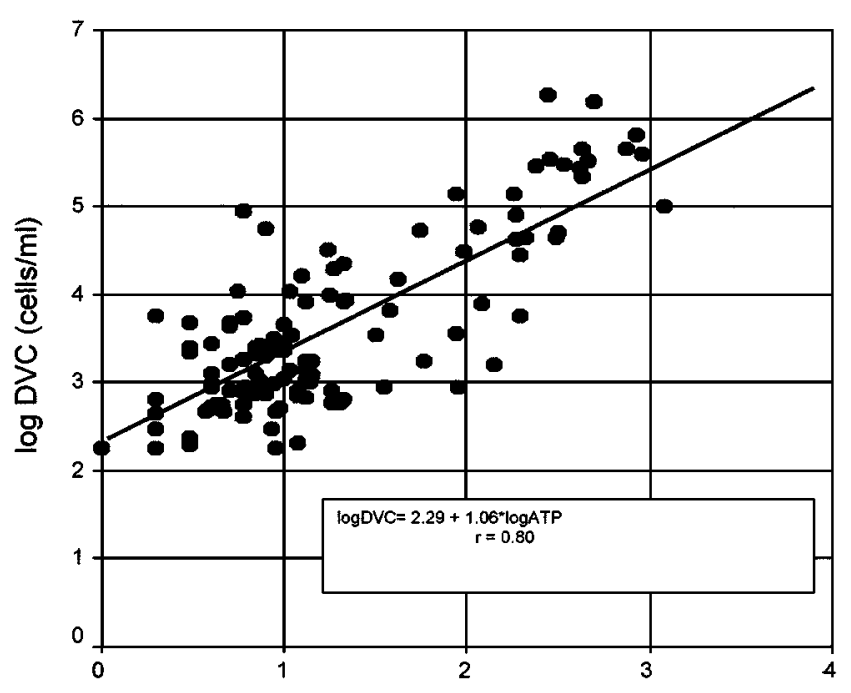

$\log$ ATP (RLU/ml)

FIG. 4. ATP vs. DVC.

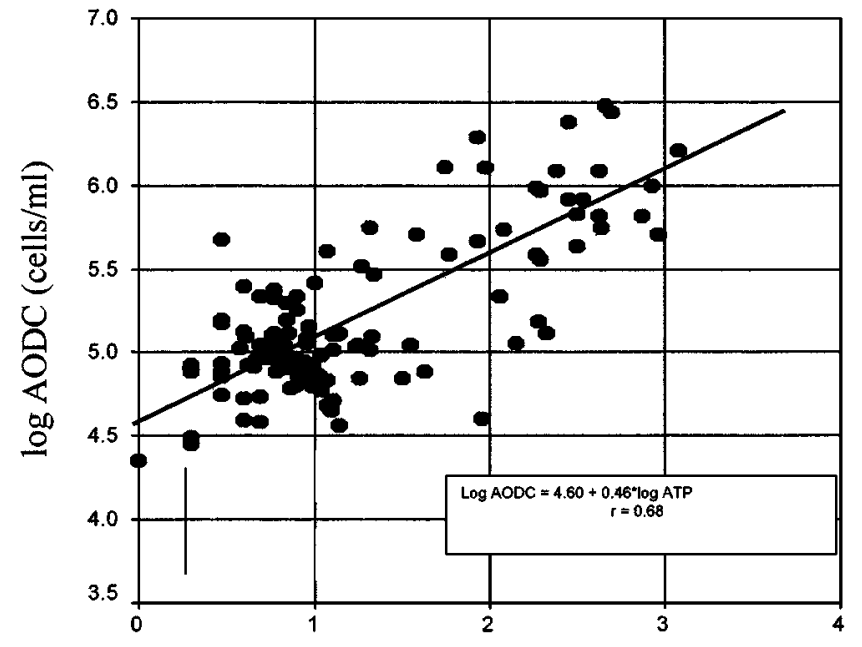

$\log$ ATP (RLU/ml)

FIG. 5. ATP vs. AODC.

of the water is necessary. An instrument exists which can do this, but the instrument and chemicals are expensive and not practical for the everyday monitoring of a supply, but quite possible for a high profile event.

\section{Conclusions}

The estimation of the heterotrophic plate count can be done in minutes. A strong correlation exists between the HPC and an ATP assay using bioluminescence allowing the prediction of the HPC from the ATP test. The samples from the United States and a large number of worldwide samples show the same relationship. For the U.S. water samples, the additional tests of a bacterial count using both the AODC and the DVC methods indicate that the ATP method is a valid test. The method is rapid and sensitive and can be done on-site with a portable power supply. The volume of water required for the test is small. Typical volumes are less than $10 \mathrm{ml}$. For very clean waters the size of the sample is dictated by the commercially available syringes. Thus, a traveler wishing to determine the bacterial water quality of a drinking water supply in the United States or a foreign country can do this in less than 5 min.

\section{References}

1. Federal Register. 1996. Vol 61, No 94, p. 24372.

2. Payment P, Richardson L, Siemiatycki J, Dewar R, Edwardes M, Franco E. A randomized trial to evaluate the risk of gastrointestinal disease due to consumption of drinking water meeting current microbiological standards. Am J Public Health 1991;81:703-708.

3. Geldreich EE, Nash HD, Reasoner DJ, Taylor RH. The necessity of controlling bacterial populations in potable waters; community water supply. J Am Water Works Assoc 1972;64:596-602.

4. LeChevallier MW, McFeters GA. Interactions between heterotrophic plate count bacteria and coliform organisms. Appl Environ Microbiol 1985;49:1338-1341. 
5. Reasoner DJ, Geldreich EE. A new medium for the enumeration and subculture of bacteria from potable water. Appl Environ Microbiol 1985; 49:1-7.

6. APHA-AWWA-WEF. Standard Methods for the Examination of Water and Wastewater 19th edition. Washington, DC: American Public Health Association, Inc.; 1995.

7. Hobbie JE, Daley RJ, Jasper S. Use of Nuclepore filters for counting bacteria by fluorescence microscopy. Appl Environ Microbiol 1977;33:1225-1228.
8. Coallier J, Prevost M, Rompre A. The optimization and application of two direct viable count methods for bacteria in distributed drinking water. Can J Microbiol 1994;40:830-836.

9. Lee JY, Deininger RA. A rapid method for detecting bacteria in drinking water. J Rapid Methods Automation Microbiol 1999;7:135-145.

10. Crombrugge J, Waes G. ATP method. In: Heeschen W, editor. Methods for Assessing the Bacteriological Quality of Raw Milk from the Farm. Brussels, Belgium: International Dairy Federation; 1991. pp 5360. 